\section{Cellular Proliferation Index between Carcinoma Ex-Pleomorphic Adenoma and Pleomorphic Adenoma}

Fernanda Viviane Mariano ${ }^{1}$, Ana Flávia Costa ${ }^{2}$, Rogério Oliveira Gondak ${ }^{3}$, Antonio Santos Martins ${ }^{4}$, André Del Negro ${ }^{4}$, Álfio José Tincani ${ }^{4}$, Albina Altemani', Oslei Paes de Almeida ${ }^{5}$, Luiz Paulo Kowalski ${ }^{2}$

\begin{abstract}
Carcinoma ex pleomorphic adenoma (CXPA) has been considered an interesting model of carcinogenesis, presenting various histological subtypes and invasiveness phase. The objective was to determine the proliferative index of CXPA and comparing to pleomorphic adenoma (PA). Thirty six cases of CXPA (36 PA) and 22 areas of PA in CXPA (residual PA) were studied by Ki-67 expression. All CXPA cases were classified according to invasiveness phase (intracapsular, minimally and frankly invasive) and histopathological subtypes. Data was statistically analyzed by Wilcoxon, Mann-Whitney and Kruskal-Wallis tests. CXPA included 5 intracapsular, 9 minimally invasive and 22 frankly invasive cases. Fifteen cases corresponded to salivary duct carcinoma, 7 to adenocarcinoma NOS, 7 myoepithelial, 5 epithelial-myoepithelial, one case of squamous cell and one case of sarcomatoid carcinoma. The Ki-67 index of PA and residual PA were significantly lower than CXPA. Intracapsular and minimally invasive showed smaller proliferative index than frankly invasive. Considering the subtypes of CXPA, there was not a statistic difference among them. $\mathrm{Ki}-67$ is a useful marker in the differential diagnosis of PA and CXPA, even when in the early invasive phase.
\end{abstract}

\author{
'Department of Pathology, \\ School of Medical Sciences, \\ UNICAMP - Universidade de \\ Campinas, Campinas, SP, Brazil \\ ${ }^{2}$ Department of Head and Neck and \\ Otorhinolaryngology, Hospital AC \\ Camargo, São Paulo, SP, Brazil \\ ${ }^{3}$ Department of Pathology, UFSC \\ - Universidade Federal de Santa \\ Catarina, Florianópolis, SC, Brazil \\ ${ }^{4}$ Department of Head and Neck, \\ School of Medical Sciences, \\ UNICAMP - Universidade de \\ Campinas, Campinas, SP, Brazil \\ ${ }^{5}$ Department of Oral Pathology, \\ Piracicaba Dental School, \\ UNICAMP - Universidade de \\ Campinas, Piracicaba, SP, Brazil
}

Correspondence: Dr. Fernanda Viviane Mariano Av. Tessália Vieira de Camargo, 126, 13083-887 CampinasSP, Brasil. Tel: +55-19-3289-3897 e-mail: fevimariano@gmail.com.br

Key Words: pleomorphic adenoma, carcinoma ex-pleomorphic adenoma, Ki-67, invasiveness, histopathological subtypes.

\section{Introduction}

Carcinoma ex-pleomorphic adenoma (CXPA) is a rare malignant tumor that affects the salivary glands, corresponding to $3.6 \%$ of all salivary neoplasms and $11.7 \%$ of all salivary malignancies. It originates from a previous PA, usually in the 6th and 7th decades of life, as a slow painless growing mass (1). CXPA is classified according to the extension of the invasion beyond the capsule of the previous PA as: intracapsular, minimally invasive and frankly invasive, with the latter showing a worse prognosis $(1,2)$. This tumor has been considered an interesting model of carcinogenesis, presenting various histological subtypes and invasiveness phase 2 .

$\mathrm{Ki}-67$ is the most used proliferative marker, and it has been helpful for diagnosis, and determination of aggressiveness and prognosis of many cancers (3-11). In CXPA, Ki-67 index can provide more objective criteria to distinguish atypical cells without malignant potential from the carcinomatous foci. A proliferative index has not yet been evaluated in the different phases of tumor carcinogenesis neither among the different histological subtypes of CXPA.

The aim of this study is to analyze the Ki-67 index in a group of CXPA (classified according to the invasiveness phase and according to the histological subtype) and a group of PA.

\section{Material and Methods}

Thirty-six cases of CXPA, 36 of PA (control PA), and 22 areas of PA in CXPA (residual PA) were studied over a 22-year period (January 1990 to December 2012) were retrieved from the archives of Pathology Department from the College of Medical Sciences from UNICAMP University of Campinas. The original hematoxylin-eosin (HEEE) stained slides were reviewed by 2 oral pathologists and the diagnoses of all cases were confirmed following the World Health Organization's 2005 Histological Typing of Salivary Gland Tumors guidelines (1). All cases of CXPA were classified according to invasiveness (intracapsular, minimally and frankly invasive phase) and histological subtype. Proliferative index was determined by $\mathrm{Ki}-67$ and the data was statistically analyzed by Wilcoxon, MannWhitney and Kruskal-Wallis tests. Probability values $<0.05$ were considered significant. Ki-67 expression was detected by immunohistochemistry, using the clone MIB-1 (1:500 dilution) as the primary antibody (Immunotech, Marseille, France). Positive control was used. EnVision plus (K4001; DakoCytomation, Kyoto, Japan) was used as the detection system, and DAB (Sigma-Aldrich-Merck, KGaA, Darmstadt, Germany) as chromogen. Quantitation was made with the help of the IMAGELAB-2000 ${ }^{\circledR}$ program (Softium, São Paulo, $S P, B r a z i l)$, counting at least 1,000 cells of each case studied and the areas with highest $\mathrm{Ki}-67$ uptake were selected. Cells 
were considered positive when the nuclei were brownstained. The study was carried out in accordance with the ethical guidelines of Piracicaba Dental School - FOP/ UNICAMP (Process number CEP/FOP 002/2011).

\section{Results}

The PA group included 12 men and 24 women, with an average of 37.1 years old, with $66.1 \%$ of the cases involving the parotid gland, followed by the minor salivary gland $(22.2 \%)$ and submandibular gland (16.6\%). Twenty-two areas de PA in CXPA (residual) were studied.

The proportion of man and women in the CXPA group was similar to the PA group, with an average of 57.5 years. Seventy five percent of the cases occurred in the parotid gland, $13.9 \%$ in submandibular gland, and $11.1 \%$ in minor salivary gland. According to the invasiveness 5 out of 36 were classified as intracapsular (no capsule invasion) (Fig. 1), 9 out of 36 were classified as minimally invasive $(<1.5 \mathrm{~mm})$
(Fig. 2), and 22 out of 36 as frankly invasive ( $>1.5 \mathrm{~mm}$ ) (Fig. 3). Salivary duct carcinoma was the most common subtype (15 cases, 41.7\%), followed by adenocarcinoma NOS (7 cases, 19.4\%), myoepithelial carcinoma (7 cases, 19.4\%), epithelial-myoepithelial carcinoma (5 cases, $13.9 \%)$ and one case of squamous cell carcinoma (2.8\%) and one case of sarcomatoid carcinoma (2.8\%).

$\mathrm{Ki}-67$ index for PA, for residual areas of PA in CXPA and for CXPA were $6.7 \%, 6.9 \%$, and $49.3 \%$, respectively. The comparison between control PA and CXPA, and between residual PA and CXPA was considered statistically significant (Table 1). The analysis between residual PA areas and malignant regions of CXPA was statistically significant in higher degree cases (salivary duct carcinoma and adenocarcinoma NOS) (Table 2). There were no statistical differences among the histological subtypes of CXPA (Table 2). Higher values were found in sarcomatoid and squamous carcinomas, but they corresponded only to 1
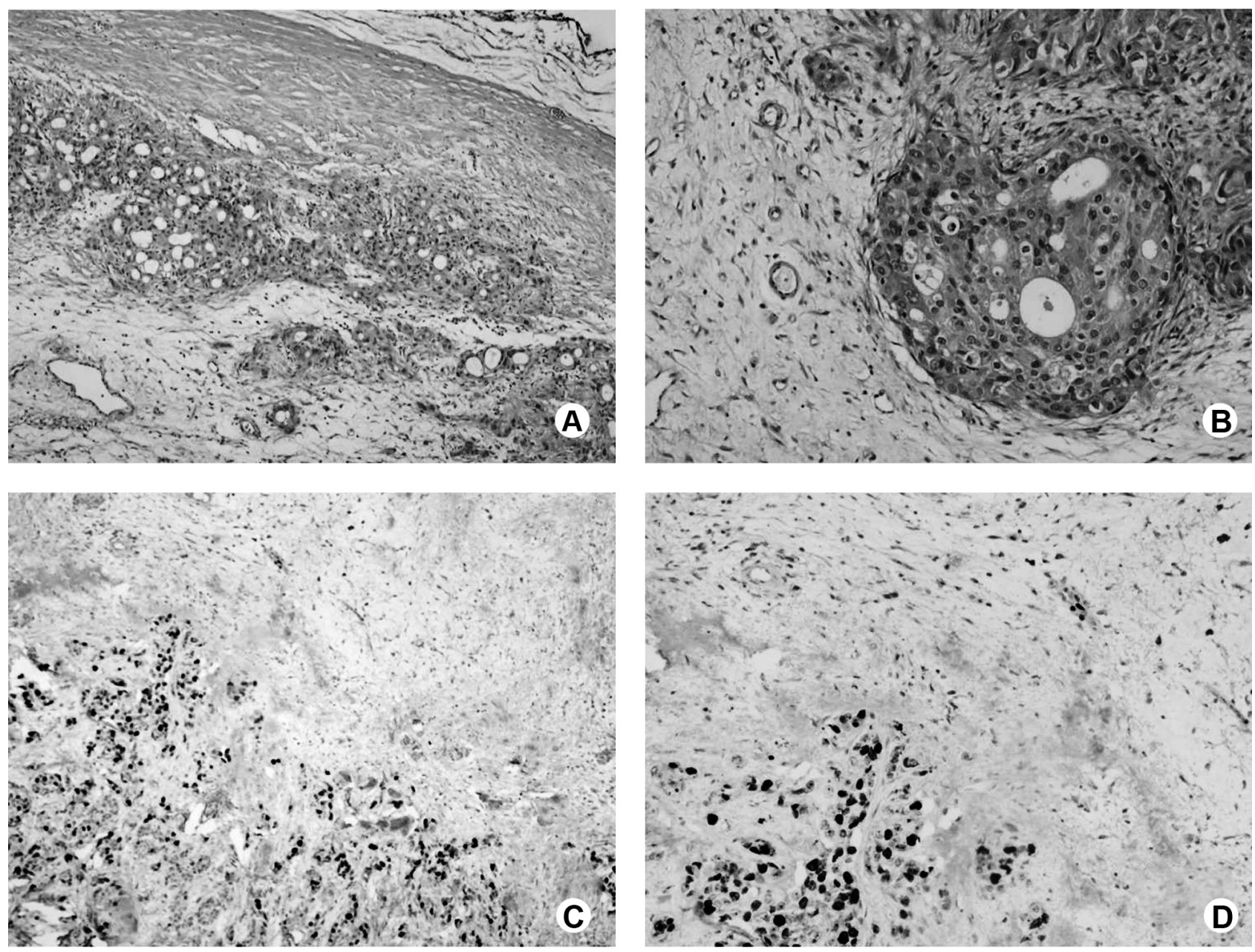

Figure 1. Intracapsular salivary duct carcinoma. A: Nests of malignant cells contained by the fibrous capsule (HE, 10x). B: Small nest of carcinomatous ductal epithelium with moderate cellular and nuclear pleomorphism. Note that the carcinoma arises in a residual pleomorphic adenoma (HE, 40x). C: Ki-67 nuclear expression in the nests of malignant cells and the benign cells (residual pleomorphic adenoma) with low positivity (HE, 10x). D: Feature cells with greater detail (HE, 20x). 
case each (Table 2).

According to invasiveness of CXPA, the values of Ki67 index were higher in frankly and minimally invasive carcinomas compared to intracapsular, but it was not statistically significant $(p=0.077)$ as shown on Table 3 . The values were statistically significant when the residual PA and CXPA were compared in all the phases of invasiveness (Table 3).

\section{Discussion}

Carcinoma ex-pleomorphic adenoma is rare, presenting various subtypes and phases of invasiveness, leading to different biological behavior and prognosis. The concept of in-situ or intracapsular carcinoma in CXPA was introduced by LiVolsi and Perzin in 1977 (12). Tortoledo et al. (1984) (13) confirmed the significance of the prognosis of neoplastic extension beyond the capsule of CXPA using objective measurements. However regional metastatic dissemination from intracapsular CXPA and deaths from minimally invasive CXPA were reported (14-16). It is well knowed that frankly invasive cases have a worse prognosis.

Diagnosis of early CXPA can be challenging, as the atypical cellular features and the area involved can be minimal and criteria to help the diagnosis have not yet been fully established (17). Hypercellularity, capsule invasion, hyalinization, necrosis, cellular and nuclear atypia, and mitosis may be important features that could indicate an increased risk to malignant change $(18,19)$. Because of difficulties in the diagnosis and to better understand malignant progression of CXPA, molecular and immunohistochemical studies have been performed. The p53 and c-erB-2 proteins seem to be involved in the early phases of malignant transformation of $\mathrm{PA}$, and therefore they can be potentially useful for the diagnosis (20).

$\mathrm{Ki}-67$ is a reliable marker of cellular proliferation, which is the hallmark of malignant transformation and progression. In fact, various authors used Ki-67 to better understand the biology of CXPA and its value as a prognostic
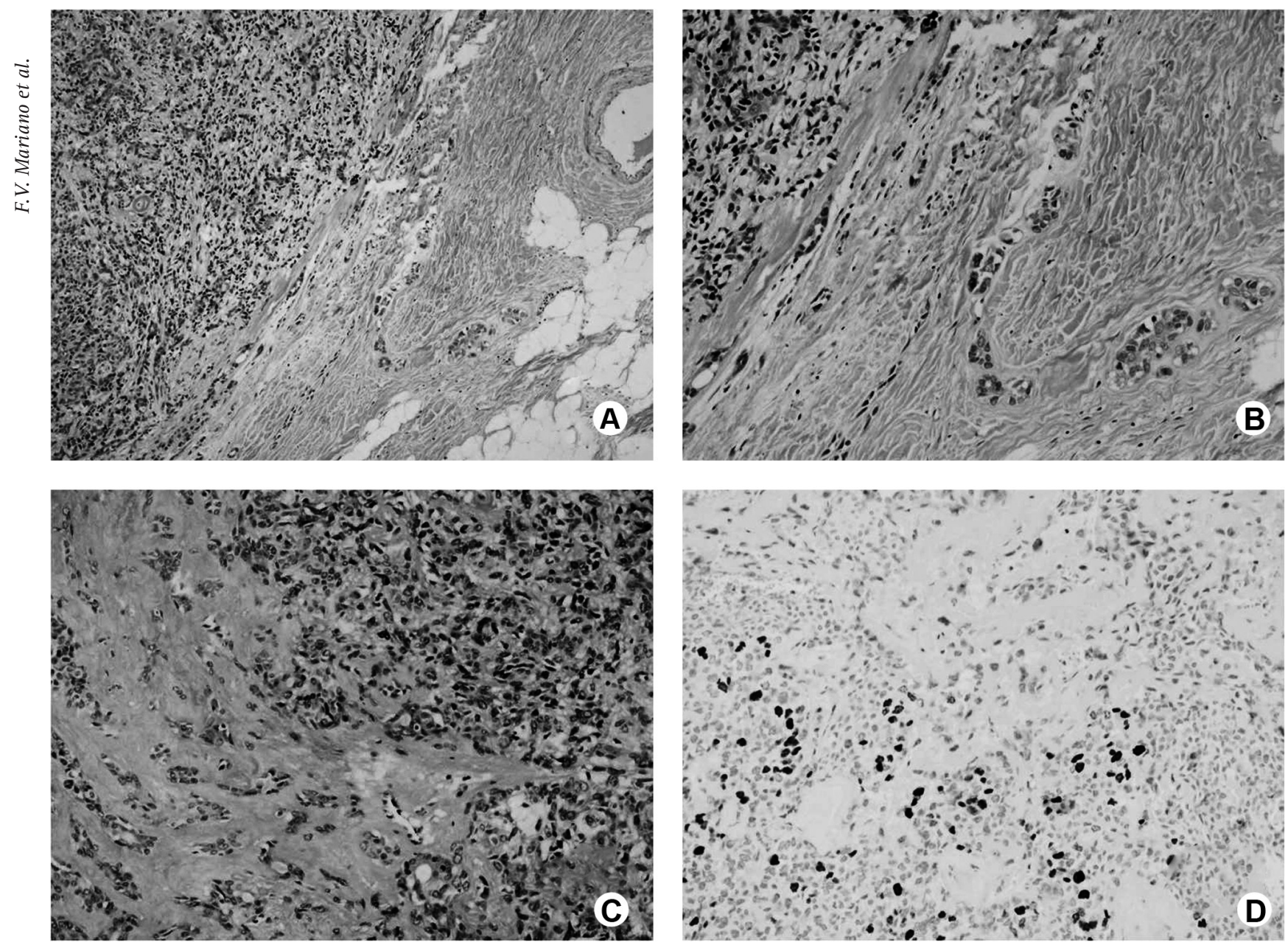

Figure 2. Minimally invasive myoepithelial carcinoma. A: Myoepithelial carcinoma in a nodular pattern of growth showing cord of myoepithelial cells extending to adjacent tissue (HE, 10x). B: Greater detail of invasion of malignant cells (HE, 20x). C: Proliferation of myoepithelial carcinoma arising in residual pleomorphic adenoma (HE 20x). D: Positive Ki-67 expression in malignant area and negativity in benign area (HE, 20x). 
marker $(9,17,21)$. In addition, Ki-67 index can be considered a useful tool in distinguishing PA from CXPA, because Ki-67 index in CXPA is significantly higher in the carcinomatous areas (20). Our findings confirmed these observations, showing that CXPA presents a higher proliferative index than the PA and than the residual PA in CXPA. On the other hand, there was no statistically significant difference between PA and residual PA.
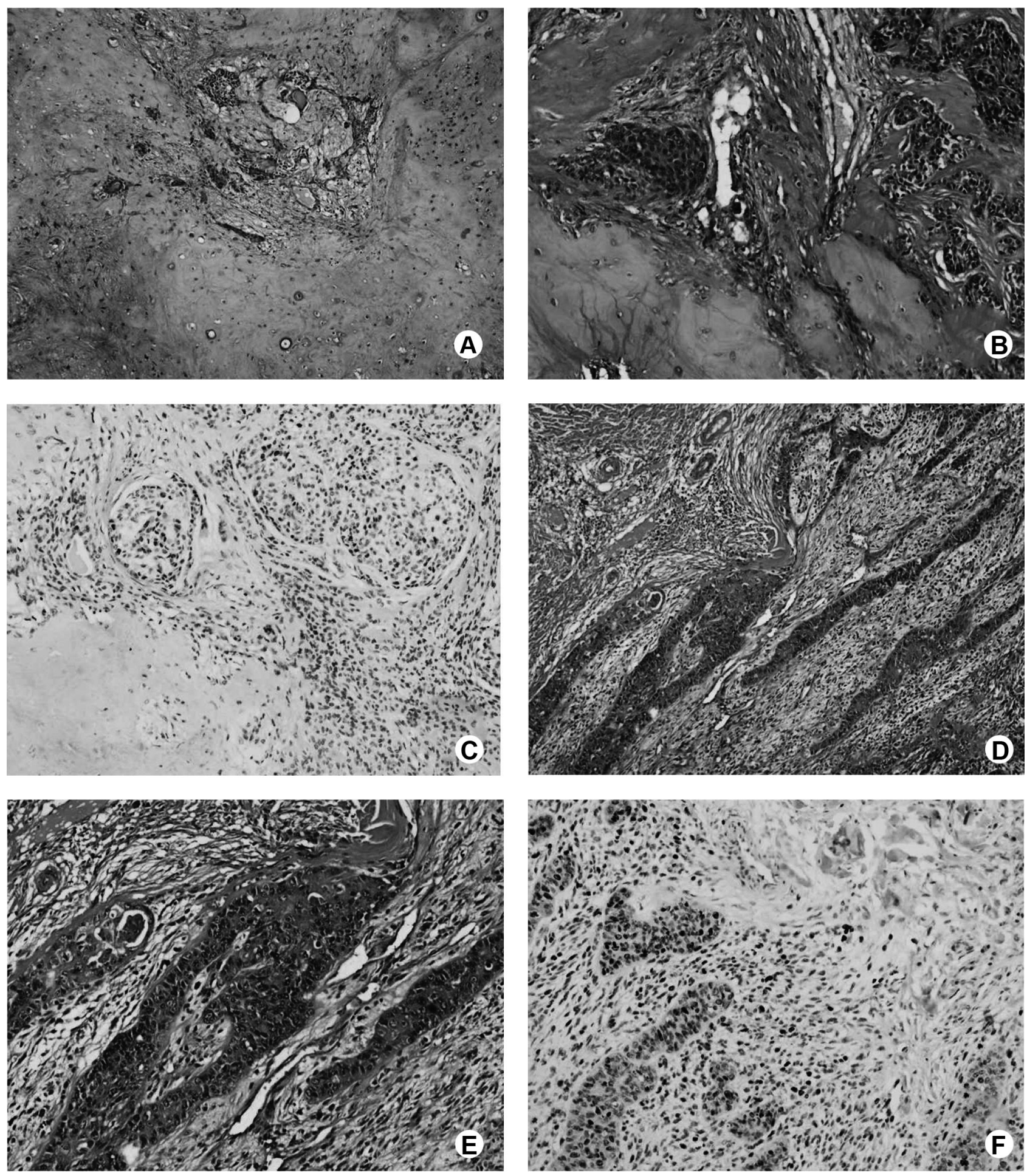

Figure 3. Frankly invasive sarcomatoid carcinoma. A: Residual pleomorphic adenoma showing an admixture of epithelial, myoepithelial and stroma components (HE, 10x). B: Transition area between benign and malignant region (HE, 20x). C: Ki-67 expression in transition area showing beginning of positivity (HE, 20x). D: Proliferation of malignant epithelial cord and fusiform mesenchymal cells. Note that the carcinomatous and sarcomatous components are intermixed (HE, 10x). E: Cellular and nuclear pleomophism, hyperchromatism and invasive growth were observed in both components (HE, 20x). F: Ki-67 expression in malignant and benign areas. Observe the positivity in carcinomatous and sarcomatous elements (HE, 20x). 
The proliferative index showed no significant differences among the histological subtypes of CXPA, but in our series we had only intermediate and high-grade tumors. In fact sarcomatoid and squamous cell carcinoma showed very high values ( $75.4 \%$ and $81.1 \%$ of positive cells, respectively), but we had only one case each, precluding a definitive conclusion. When the progression from residual PA to CXAP among the different histopathological subtypes is evaluated, the duct salivary carcinoma and adenocarcinoma NOS are statically significant and the other subtypes (epithelial-myoepithelial carcinoma and myoepithelial carcinoma) present strong tendency for significance. Katori et al. (2007) (22) also found a significant increase of the Ki-67 index in CXPA, especially in adenocarcinoma NOS. However, there are controversies regarding to aggressiveness of each histopathological subtype (16).

In short Ki-67 seems to be useful to help to detect initial areas with malignant transformation, it does not help to better characterize the histological subtypes. It is recommended to classify the histological subtypes by morphology. As that PA undergoes malignant change, the Ki-67 index increases. The aggressiveness is better evaluated by histological invasiveness of the capsule and adjacent tissues.

Frankly invasive CXPA showed a proliferative index higher than those in intracapsular and minimally invasive phases, but it was not statistically significant. Significance was observed when intracapsular and frankly invasive phases were analyzed showing that the minimally invasive phase is an intermediate stage and should be morphologically recognized.

In conclusion, proliferative index determined by Ki-67 is an useful for differential diagnosis of PA and CXPA, even in the early invasive phase, as the values in the carcinomatous areas are higher than in PA.

Table 1-Ki-67 index (\%) in PA, areas of residual PA in CXPA and CXPA group.

\begin{tabular}{|c|c|c|c|c|c|c|c|}
\hline Cases & $\mathrm{N}$ & Min & Max & Mean \pm SD & Control PA x Residual PA & Control PA x CXPA & Residual PA x CXPA \\
\hline Control PA & 36 & 1.6 & 11.5 & $6.7 \pm 2.5$ & \multirow{3}{*}{$p=0.278^{*}$} & \multirow{3}{*}{$p=0.000^{*}$} & \multirow{3}{*}{$p=0.000^{* * *}$} \\
\hline Residual PA & 22 & 0.6 & 30.2 & $6.9 \pm 8.2$ & & & \\
\hline CXPA & 36 & 11.6 & 86.2 & $49.3 \pm 21.7$ & & & \\
\hline
\end{tabular}

*Mann-Whitney test; **Wilcoxon test.

Table 2. Ki-67 mean index according to histopathological subtypes comparing residual PA and CXPA, and among all CXPA cases.

\begin{tabular}{|c|c|c|c|c|c|c|}
\hline \multirow{2}{*}{ Histopathological subtypes } & \multicolumn{2}{|r|}{ CXPA } & \multicolumn{2}{|r|}{ Residual PA } & \multirow{2}{*}{$\frac{\text { Wilcoxon test }}{\text { CXPA and Residual PA }}$} & \multirow{2}{*}{$\begin{array}{l}\text { Kruskal- Wallis test } \\
\text { All cases of CXPA }\end{array}$} \\
\hline & $\mathrm{N}$ & Mean \pm SD $(\%)$ & $\mathrm{N}$ & Mean \pm SD (\%) & & \\
\hline Adenocarcinoma NOS & 7 & $59.3 \pm 22.6$ & 5 & $6.7 \pm 10.1$ & $p=0.043$ & \multirow{6}{*}{$p=0.294$} \\
\hline Salivary duct carcinoma & 15 & $42.7 \pm 18.8$ & 8 & $4.1 \pm 4.1$ & $p=0.012$ & \\
\hline Epithelial-myoepithelial carcinoma & 5 & $44.3 \pm 20.0$ & 4 & $10.2 \pm 13.4$ & $p=0.068$ & \\
\hline Myoepithelial carcinoma & 7 & $48.6 \pm 24.8$ & 4 & $11.1 \pm 6.8$ & $p=0.068$ & \\
\hline Sarcomatoid carcinoma & 1 & $75.4^{*}$ & 0 & 0 & 0 & \\
\hline Squamous cell carcinoma & 1 & $81.1^{*}$ & 0 & 0 & 0 & \\
\hline
\end{tabular}

$\mathrm{N}=$ Number; $\mathrm{SD}=$ Standard deviation; *Absolute number.

Table 3. Ki-67 mean index according to degree of invasiveness comparing residual PA in CXPA, and among all CXPA cases.

\begin{tabular}{|c|c|c|c|c|c|c|}
\hline \multirow{2}{*}{ Invasiveness } & \multicolumn{2}{|r|}{ CXPA } & \multirow{2}{*}{$\begin{array}{c}\text { Kruskal Wallis } \\
\text { All cases of CXPA }\end{array}$} & \multicolumn{2}{|c|}{ Residual PA } & \multirow{2}{*}{$\begin{array}{c}\text { Mann-Whitney } \\
\text { CXPA and residual PA }\end{array}$} \\
\hline & $\mathrm{N}$ & Mean \pm SD $(\%)$ & & $\mathrm{N}$ & Mean \pm SD $(\%)$ & \\
\hline Intracapsular & 5 & $29.7 \pm 23.2$ & & 4 & $3.6 \pm 1.0$ & $p=0.016$ \\
\hline Minimally invasive & 9 & $52.3 \pm 19.3$ & $p=0.077$ & 8 & $7.8 \pm 8.2$ & $\mathrm{p}<0.001$ \\
\hline Frankly invasive & 22 & $52.4 \pm 20.7$ & & 9 & $4.9 \pm 6.3$ & $\mathrm{p}<0.001$ \\
\hline
\end{tabular}




\section{Resumo}

Carcinoma ex adenoma pleomorfo (CXAP) tem sido considerado um interessante modelo de carcinogênese, apresentando vários subtipos histológicos e fases de invasividade. Determinar o índice proliferativo de CXAP e compará-lo ao adenoma pleomorfo (AP). e seis casos de CXAP, 36 AP, e 22 áreas de AP em CXAP (AP residual) foram estudadas através da expressão de Ki-67. Todos os casos de CXAP foram classificados de acordo com a fase de invasividade (intracapsular, minimamente invasivo e francamente invasivo) e de acordo com os diversos subtipos histopatológicos. Os dados foram estatisticamente analisados através dos testes Wilcoxon, Mann-Whitney e Kruskal-Wallis. 0 grupo de CXAP era formado por 5 intracapsulares, 9 minimamente invasivos e 22 francamente invasivos. Quinze casos corresponderam a carcinoma de ducto salivar, 7 a adenocarcinoma nos, 7 a carcinoma mioepitelial, 5 a carcinoma epitelialmioepitelial, 1 a carcinoma epidermoide e 1 a carcinoma sarcomatóide. 0s índices de Ki-67 de AP e AP residual foram significativamente menores que o encontrado em CXAP. Os casos intracapsulares e minimamente invasivos mostraram indices proliferativos menores que os francamente invasivos. Considerando os subtipos histológicos de CXAP, não houve diferença estatística entre eles. Ki-67 é um marcador útil no diagnóstico diferencial de AP e CXAP, mesmo quando o carcinoma está em fase precoce de invasividade.

\section{Acknowledgements}

This work was funded by FAPESP (The São Paulo State Research Foundation), Grants\#2011/ 23366-5 and 2011/ 23204-5.

\section{References}

1. Gnepp DR, Brandewein-Gensler MS, El-Nagger AK, Nagao T. Carcinoma ex pleomorphic adenoma. In: Barnes L, Eveson JW, Reichart P, Stdransky D, editors. World Health Organization Classification of Tumours. Pathology and Genetics of Head and Neck Tumours. Lyon: IARC press; 2005. p. 242-243.

2. Olsen KD, Lewis JE. Carcinoma ex pleomorphic adenoma: a clinicopathologic review. Head Neck 2001:23:705-712.

3. Laitinen $\mathrm{S}$, Martikainen PM, Tolonen $\mathrm{T}$, Isola J, Tammela TL, Visakorpi T. EZH2, Ki-67 and MCM7 are prognostic markers in prostatectomy treated patients. Int J Cancer 2008:122:595-602.

4. Vacchi-Suzzi M, Bocciolini C, Bertarelli C, Dall'Olio D. Ki-67 proliferation rate as a prognostic marker in major salivary gland carcinomas. Ann Otol Rhinol Laryngol 2010:119:677-683.

5. Aune G, Stunes AK, Tingulstad S, Salvesen O, Syversen U, Torp SH. The proliferation markers Ki-67/MIB-1, phosphohistone H3, and survivin may contribute in the identification of aggressive ovarian carcinomas. Int J Clin Exp Pathol 2011:4:444-453.

6. Habberstad AH, Gulati S, Torp SH. Evaluation of the proliferation markers Ki-67/MIB-1, mitosin, survivin, pHH3, and DNA topoisomerase Il $\alpha$ in human anaplastic astrocytomas--an immunohistochemical study. Diagn Pathol 2011:24:43-50.

7. Kapur P, Lotan Y, King E, Kabbani W, Mitra AP, Mosbah A, et al.. Primary adenocarcinoma of the urinary bladder: value of cell cycle biomarkers. Am J Clin Pathol 2011:135:822-830.

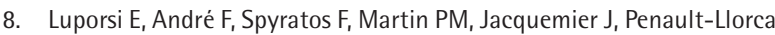
F, et al.. Ki-67: level of evidence and methodological considerations for its role in the clinical management of breast cancer: analytical and critical review. Breast Cancer Res Treat 2012:132:895-915.

9. Seethala RR. Histologic grading and prognostic biomarkers in salivary gland carcinomas. Adv Anat Pathol 2011:18:29-45.

10. Tang QL, Fan S, Li HG, Chen WL, Shen XM, Yuan XP, et al.. Expression of Cyr61 in primary salivary adenoid cystic carcinoma and its relation to Ki-67 and prognosis. Oral Oncol 2011:47:365-370.

11. Yang Z, Tang LH, Klimstra DS. Effect of tumor heterogeneity on the assessment of $\mathrm{Ki}-67$ labeling index in well-differentiated neuroendocrine tumors metastatic to the liver: implications for prognostic stratification. Am J Surg Pathol 2011:35:853-860.

12. LiVolsi VA, Perzin KH. Malignant mixed tumors arising in salivary glands. Carcinomas arising in benign mixed tumors: a clinicopathologic study. Cancer 1977:39:2209-2230.

13. Tortoledo ME, Luna MA, Batsakis JG. Carcinoma ex pleomorphic adenoma and malignant mixed tumors. Histomorphologic indexes. Arch Otolaryngol 1984:110:172-176.

14. Lewis JE, Olsen KD, Sebo TJ. Carcinoma ex pleomorphic adenoma: pathologic analysis of 73 cases. Hum. Pathol 2001:32:596-604.

15. Felix A, Rosa-Santos J, Mendonça ME, Torrinha F, Soares J. Intracapsular carcinoma ex pleomorphic adenoma. Report of a case with unusual metastatic behaviour. Oral Oncol 2002:38:107-110.

16. Katabi N, Gomez D, Klimstra DS, Carlson DL, Lee N, Ghossein R. Prognostic factors of recurrence in salivary carcinoma ex pleomorphic adenoma, with emphasis on the carcinoma histologic subtype: a clinicopathologic study of 43 cases. Hum Pathol 2010:41:927-934.

17. Di Palma S, Skálová A, Vanièek T, Simpson RH, Stárek I, Leivo I. Noninvasive (intracapsular) carcinoma ex pleomorphic adenoma: Recognition of focal carcinoma by HER-2/neu and MIB1 immunohistochemistry. Histopathology 2005:46:144-152.

18. Auclair PL, Ellis GL. Atypical features in salivary gland mixed tumors: Their relationship to malignant transformation. Mod Pathol 1996:9:652-657

19. Takeda Y. An immunohistochemical study of bizarre neoplastic cells in pleomorphic adenoma: its cytological nature and proliferative activity. Pathol Int 1999:49:993-999.

20. Freitas LL, Araújo VC, Martins MT, Chone C, Crespo A, Altemani A. Biomarker analysis in carcinoma ex pleomorphic adenoma at an early phase of carcinomatous transformation. Int J Surg Pathol 2005:13:337-342.

21. Katori H, Nozawa A, Tsukuda M. Increased expression of cyclooxygenase-2 and Ki-67 are associated with malignant transformation of pleomorphic adenoma. Auris Nasus Larynx 2007:34:79-84.

22- Katori H, Nozawa A, Tsukuda M. Expression of epidermal growth factor receptor, transforming growth factor-alpha and $\mathrm{Ki}-67$ in relationship to malignant transformation of pleomorphic adenoma. Acta Otolaryngol 2007:127:1207-1213.

Received December 4, 2014 Accepted April 10, 2015 